\title{
Inheritance and Application of Chinese Traditional Elements in Modern Logo Design
}

\author{
Bing Liu ${ }^{1, a}$, Ruiqiu Pang ${ }^{2, b^{*}}$ \\ ${ }^{1}$ Academy of Fine Arts, Northeast Normal University, Changchun130024, China \\ ${ }^{2}$ School of Geographical Sciences, Northeast Normal University, Changchun130024, China \\ a ice8515@163.com, br rq56789@yeah.net
}

\begin{abstract}
Logo is the visual carrier of enterprise brand image and the key factor of brand strategy, this paper studies the integration of Chinese traditional art elements and logo design, the research shows, continuation and extension of Chinese traditional graphics, grasp and inherit Chinese traditional color, the comprehensive application of the methods of extraction and derivation of Chinese characters, can make the logo design with rich styling appearances and profound meanings of decoration, the organic combination of traditional elements and modern design, is great significance to the reform and development of logo design; The reappearance of Chinese traditional elements in logo design is the exploration, deepening and extension of traditional culture, the combination of Chinese elements and the requirements of the times, so that logo design presents the form of beauty, brand connotation and cultural heritage, to better serve the enterprise brand strategy.
\end{abstract}

Keywords: Chinese traditional elements; Logo design; Inheritance and application

\section{Introduction}

China traditional culture has a long history and glorious and resplendent, and made great contributions to the progress of mankind, these traditional Chinese elements with the passage of time and the history of the development of continuous precipitation, extension, evolution, to form a unique traditional Chinese art system, this system embodies the wisdom of the Chinese nation for thousands of years, at the same time, it also reflects the unique artistic spirit of the Chinese nation. With China's reform and opening up, the design of the excellent logo appears continuously, the interaction between logo design and economy provides designers with a broad space for development and creation. Logo design in promoting China's cultural and economic development, and the exchanges and cooperation between China and the world in the fields of politics, culture and economy, all play an important role $[1,2]$.

Chinese civilization has a long history, the unique geographical and cultural environment has created a unique cultural connotation, Chinese traditional elements have a strong cultural heritage, with strong and broad tolerance, designers need to deeply grasp the traditional Chinese elements, and combine them perfectly with modern design elements, give the traditional elements of a new era of mission and life. Using Chinese traditional elements to design logo, more likely to cause people's emotional resonance, it is helpful to the identification and dissemination of modern signs [3].

\section{Chinese Traditional Elements and Logo Design}

\subsection{Analysis of Chinese Traditional Elements}

Chinese traditional culture, is a national culture that reflects national characteristics and style, it is the general representation of various ideological and cultural concepts in the history of the nation, it was created by the Chinese nation and its ancestors, with distinctive national characteristics, and has a long history and profound connotation and so on.

Chinese traditional elements come from Chinese traditional culture, China's Millennium culture heritage, extracted from the representative of the elements, the condensation of the Chinese nation for thousands of years of civilization wisdom, but also carry forward the spirit of the Chinese nation's art, to bring people yearning for a happy and happy life. Chinese elements are all inclusive, rich in content, a variety of situations, a simple graphic language has a very deep meaning, is the other art situation cannot be replaced and compared. After five thousand years of cultural heritage, a wide 
variety of Chinese elements, rich in meaning, for example, Chinese calligraphy, seal, ancient coins, Chinese knot, embroidery, ink painting, paper cutting, Chinese characters and so on, which should be used for logo design elements: totem, tile, Paper cutting, seal, Chinese calligraphy, auspicious patterns, opera masks, etc., modeling and color of all kinds of material cultural heritage.

The application of Chinese traditional elements in modern logo design, it not only has the beauty of form of traditional symbols, more importantly, the spiritual beauty of the mind, this is the key to the design of modern logo with Chinese traditional culture. Chinese traditional elements, has become a popular fashion, it is widely used in modern logo design, to promote the Chinese civilization to the world, and will promote China's design concept to the world.

\subsection{Analysis of Logo Design}

Logo design is a kind of special text or image of the mass communication symbols, expression means to convey the content into a graphical language, to express ideas and abstract concepts in form and color, to represent the nature and essence of something, affect the viewer's attitudes, opinions and emotions, to achieve the purpose of establishing brand image. Logo design is an important part of visual communication system, the meaning of communication is to let the audience understand its cultural connotation from the graphic language, the specific things and ideas, through the abstract graphical symbols, as a bridge between enterprise and audience, to get people to see signs, get familiar with and receive [4].

Logo, reflecting the different characteristics of the times, nationality, country, region and so on, It covers all aspects of society, government agencies, schools, medical institutions at all levels, industrial and commercial enterprises, sports activities, etc., modern logo design is the carrier of human civilization, and it is the epitome of human culture. In modern commodity society, the mark belongs to the category of modern design, in the modern logo design; there are a lot of Chinese traditional elements, it contains the beauty of national culture and modern design.

In recent years, the domestic design circles on how to inherit Chinese traditional culture, made unremitting exploration and practice, they are in the works, combination of Chinese traditional culture elements and modern logo design, the emergence of a large number of outstanding design works. These works not only embody the concept and fashion of modern logo design, it also reflects the different historical and cultural characteristics and aesthetic orientation of the Chinese nation and region, and it shows the artistic charm of the combination of traditional culture and modern logo design.

\section{The Inheritance and Application of Chinese Traditional Elements in Modern Logo Design}

Chinese traditional elements are the crystallization of Five thousand years of history and human wisdom, in the modern logo design, Chinese elements are mainly represented by traditional art graphics, domestic designers use and extend the traditional Chinese graphics and color, the extraction and derivation of Chinese characters, the Chinese elements are summarized and abstracted, made the logo design is vivid, with a pregnant meaning, it is the essence of Chinese traditional culture and the embodiment of the sense of nationality.

\subsection{The Continuation and Extension of Chinese Traditional Graphics in Modern Logo Design}

Chinese traditional graphic elements are an important modeling element and style in traditional art. The development of Chinese traditional graphic art has a history of thousands of years; the earliest text is to communicate through graphics to convey their ideas. By means of modern design and construction, the traditional graphic symbols will be reorganized and refined, accurate and in-depth expression of emotion, the logo is designed in this way, not only can retain the charm of traditional art, and with a distinct sense of the times, it can fully embody the idea and individuality of the sign.

The characteristics of Chinese traditional graphics: Multi national characteristics, broad regional and rich traditional art, it pays attention to the Wholeness of form, decorative and ideographic, the composition emphasizes change and unity. Therefore, designers should understand the connotation of traditional graphics, to grasp the main features, pay attention to the details of the key parts and characterization, learn to extract the elements from the traditional graphics, combined with the 
modern graphics, scattering, cutting, intersection, dislocation, variation, combination and other means, first, the traditional graphics in the shape of the decomposition and transformation, then, the reconstruction of the new graphics combined to modern graphic design. This design of the logo, not only contains the traditional charm, but also has a distinct sense of the times.

The auspicious cloud pattern in Chinese traditional culture is the typical embodiment of the aesthetic law, common in stone carving, woodcarving, paper cutting, clothing, traditional crafts and other forms of art. Auspicious cloud pattern rich image, change, vivid, smooth, with unique artistic conception, therefore, it is widely used in modern logo design, the form, concise and profound meaning, embodies the modern sense of strong.

\subsection{The Grasp and Inherit Chinese Traditional Color in Modern Logo Design}

Color is one of the important forms of aesthetic expression; it is not only a feeling but also a kind of information. The traditional color fusion of different living environment and social environment and other factors, in the long-term natural and cultural environment, have different regional color form and color view. Traditional color is rich in cultural connotations, it is a form of traditional culture, and these traditional color concepts provide a rich visual language for modern logo design. Under the influence of traditional culture, people's visual aesthetic concept has a subjective initiative, for example, "Chinese red" is a representative color in Chinese traditional color, to give a positive and enthusiastic visual psychological reflection, at the same time, it is also a symbol of good luck and happiness, in Chinese traditional festivals or international activities, the logo on behalf of china, often showing the "Chinese red" color characteristics.

Traditional decorative color, with pure, concise and lively artistic features, the traditional color in the modern logo design, it can make the reader and the logo produce an emotional effect. The use of color in China, since ancient times, has a symbolic color tradition, for example, the traditional idea of five colors, yellow for the loess, soil in the central, yellow for the emperor's special color. Chinese traditional concept of color has long formed a simple color concept, such as red and yellow, red and green, yellow and black and other colors with the concept, integrate these ideas into logo design, it can make the logo design have both contrast and harmony, and contains rich cultural connotations.

\subsection{Extractions and Derivation of Chinese Characters in Modern Logo Design}

Ancient Chinese characters across thousands of years, is the most imaginative and abstract figure in Chinese traditional graphics, full of exuberant vitality and unique artistic charm, Chinese characters as the basic tool for human to transmit information, In order to communicate more easily and quickly, from the concrete to the image and then into the abstract $[5,6]$. On the basis of Chinese characters in ancient times, after thousands of years of history, by means of pictographic, understanding and other means to convey a specific ideographic, it has the characteristics of "graphic" and "symbolization", Chinese characters are the most influential visual symbols in Chinese elements, inscriptions on bones or tortoise shells of the Shang Dynasty, seal character, clerical script, regular script and so on, each of which represents a different connotation and artistic beauty, all of these provide abundant resources for modern logo design [7].

The use of many traditional Chinese elements is pluralistic coexistence, for example, the Bank of China, the emblem of the 2008 Olympic games, China Post and other logo, it is a combination of calligraphy and seal cutting, traditional graphics and other forms and concepts. This multiple complementary creative ideas not only enhance the cultural connotation, and are conducive to the implementation of the design concept and enhance the visual appeal [8].

\section{Conclusions}

Traditional culture is the precipitation of civilization on the Chinese nation five thousand years, in essence, the relationship between modern design and Chinese traditional art is the existence of nature. Under the premise of globalization, informationization and rapid development, Logo is a symbol of corporate image; it contains the characteristics and cultural connotation of the enterprise, and represents the core value of the enterprise brand, the logo of success is the intangible assets of an enterprise, and deeply rooted in the minds of consumers. 
Re understanding of traditional culture with modern aesthetic concept, on the basis of fully understanding of Chinese traditional culture, to convey its charm, in order to make the traditional culture in the modern logo design to be more far-reaching development and extension, with the unique influence of signs, promote the communication between eastern and Western cultures; The connotation and essence of Chinese traditional elements are integrated into the modern logo design, to restore the traditional Chinese culture with modern design concept, in the traditional culture, new ideas are derived, through the logo design shows Chinese traditional elements and culture, so that the national cultural spirit and the world's design language, into the trend of modern design, thus promoting the development of Chinese logo design.

\section{Corresponding Author}

Ruiqiu Pang, Associate Professor, Northeast Normal University, CHINA, rq56789@yeah.net.

\section{References}

[1] Duan Hongjiao, Zhang Li: Brief Analysis on the Application of Chinese Traditional Elements in Modern Logo Design, Lecture Notes in Information Technology, Vol. 37 (2012), p. 212-215.

[2] Chen Xinhua, Liu Feifei, Cai Duanyi: Analysis of Design Innovation of Self-owned Brand Logo Image, Packaging Engineering, Vol.31 (2010), p. 70-73.

[3] The Brand Identity Renewal Strategy caused by the target shift.-Focusing on the brand logo and the label design of Yang-saeng-ju.-, Archives of Design Research, Vol. 20 (2007), p. 111-120.

[4] Bae woo ri, Chung Hye Uk, A study on the color scheme of Brand Logo design -based on the 2015 top 100 most valuable global brands by Millward Brown, Design Convergence Study, Vol. 16 (2017), p. 77-95.

[5] FanWei: The Design Composition on Chinese Character of Symbol, Journal of Communication Design, Vol.51 (2015), p. 125-134.

[6] Bing Liu, Ruiqiu Pang: Reflections on the Design and Application of Modern Chinese Characters, Advances in Economics, Business and Management Research, Vol.34 (2017), p.91-94.

[7] Weidong Tang: Exploration of the Application Mode of Chinese Characters in the Logo Design, Packaging Engineering, Vol. 36 (2015), p. 99-101.

[8] He Jing: Issues with "Chinese Characteristics" in Present Chinese Logo Design, Packaging Engineering, Vol.32 (2011), p. 98-101. 